\title{
Application of Neural Networks to Power Systems for Electrical Load Forecasting
}

\author{
${ }^{1}$ Mithilesh Singh and ${ }^{2}$ Shubhrata Gupta \\ ${ }^{1}$ Associate Professor, Department of Electrical and Electronics Engineering, Kruti Institute of \\ Technology and Engineering (C.S.V.T.U.) Raipur, C.G.492001 \\ ${ }^{2}$ Senior IEEE member, Professor Electrical, N.I.T. Raipur, (C.G.) 492010 \\ Corresponding author: Email: mithileshsinghgec1996@gmail.com; Email: sgupta.ele@ nitrr.ac.in \\ Received Jan'04, 2020; received in revised form Jan'23, 2020; Accepted Jan' 25, 2020
}

\begin{abstract}
The artificial neural network system referred as parallel distributed processors conserve the information previously learnt but same time accessible to learning new information. This paper gives a brief indication of artificial neural network and its application in power system for electrical load forecasting which can further be used for enhancement of power quality. The accuracy of load forecasts has a significant effect on economy and control of power system operations for reliable and secure operation of power system. In this paper the accurate and real time data are collected from Chhattisgarh load dispatch centre of western grid of India of year 2018. This data of power flow is simulated using artificial neural network. The purpose of short-term forecasting is to satisfy as much as possible, to improve prediction accuracy.
\end{abstract}

Keywords: Artificial neural network (ANN), load forecasting, power system, power quality.

Broad Area- Electrical Engineering. Sub-Area- Neural Network.

\section{Introduction}

In order to supply high quality of electrical power proper operation in planning and control of electrical energy power system with cast saving is needed. To transmit power the knowledge of future power load is first known in advance then after long- and shortterm load forecasting is performed. The load forecasting determines the capacity of generation, transmission, distribution systems and expansion planning and maintenance scheduling etc [1]. A precise load fore casting will result in economic cost saving and improving security operation condition. The typical load forecasting would be long term, midterm, and short-term interval [2]. Traditional load forecasting method can be divided in to regression analysis and time series. The initial step for any kind of forecasting approach is to collect historical data of the system to be studied. The ANN allows more flexible relationship load patterns with temperature. The artificial intelligence method which finds a mapping between input information and future load requires a complete historical data and proper input information [3-4].

The achievements of artificial neural network are massive fast speed, high fault tolerance and adaptive capability. So, all these have attraction for controls and power systems fields to neural network solutions to some of their more complicated or unsolved problems.

Neural network applications to power systems can be categorized as regression, classification and combinational 
optimization. Artificial neural network is made up of simple highly interconnected processing units called neurons each of which perform aggregation of its inputs from other neurons and generation of an output from the aggregated inputs.

A connection between a pair of neurons has an associated numerical strength called synaptic weight. The development of ANN involves two phases: training or learning phase and testing phase. Training of ANN is done by presenting the network with examples called training patterns. During training, the synaptic weights get modified to model for that problem. As the network has learnt the problem it may be tested with new unknown patterns and its efficiency can be checked [3-4].

The back-propagation learning algorithm is the most frequently used method in training the networks [23-27], and proposed as an electrical load forecasting methodology in this paper. The back-propagation learning algorithm is a generalization of the widrowhoff error correction rule. Fig.1 shows the architecture of feed forward neural network and fig. 2 (a) shows the concept of artificial neural network. In a multilayer network (Fig. b) containing hidden a unit that is units that are neither input nor output units [23, 25].

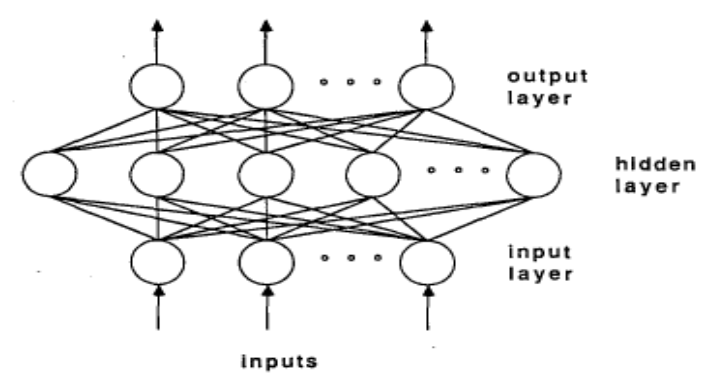

Fig. 1: Feed forward neural network

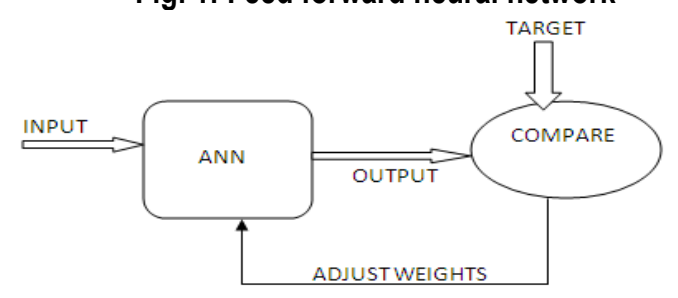

Fig. 2 (a) ANN concept

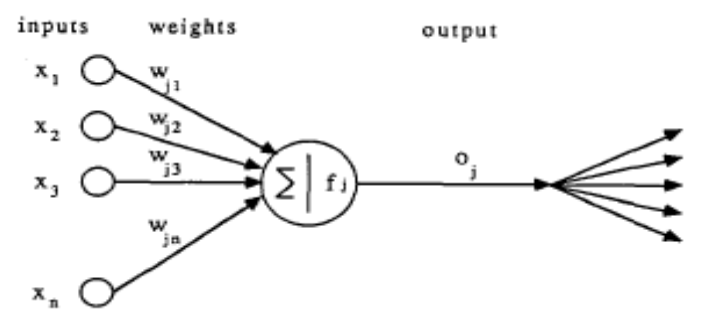

Fig. 2(b) Mathematical model of an artificial neuron

\section{Ann Applications to Power Systems for Load Forecasting:}

Several key features of neural networks techniques are learning by example in real time, distributed memory, fault tolerance and graceful degradation, real time pattern recognition, intelligent association and synthesis. The neural network traces previous load patterns and predicts a load pattern using recent load data for modeling.

Load forecasting is a suitable problem for ANN application due to the availability of historical load data on the utility databases. ANN schemes using perceptron network have been successful in short-term as well as long-term load forecasting with impressive accuracy. A combined use of unsupervised and supervised learning was done for shortterm load forecasting. The load data were analyzed and the load patterns were classified. The current load is affected by the past loads and the pattern in which the current load is included [5] [6-7].

The total number of training examples depends on the mentioned limits and assumptions, on the network architecture and the expected result error. Load Forecasting in power systems can normally be broken into the following different categories: very short forecasting of up to a few minutes ahead; forecasting for a lead time of up to a few days ahead; forecasting energy requirements over a six month or one-year period and long-term forecasting of power system peak load up to 10 years ahead. 
The traditional short-term load forecasting includes time series method, regression analysis, trend extrapolation method and expert system method [8][9][10][11].

Time series approach is based on understanding that a load pattern is nothing more than a time series signal with known seasonal, weekly, and daily periodicity. This periodicity gives a rough prediction of the load at a given time of the day. Time series model can be accurate in some situation but are complex and require some historical data. It requires careful efforts to ensure an accurate time line through the data collection filtering and processing.

Regression is one of the most widely used statistically techniques for electric load forecasting. This method is usually used for modeling between load consumption, and other factors such as weather, and type of day. The general procedure for the regression approach is to select the proper and/or available input variables; assume basic functional elements, and find proper coefficients for the linear combination of the assumed basic functional elements. The instantaneous load forecast may be used by energy management system to establish operational plans with Automatic Generation Control (AGC) which monitor and control the daily load demand [12-22].

\section{Input Variable Selection}

The data collected from state load dispatch centre Chhattisgarh state Raipur (India) is shown in Table 1:

Table 1 shows the salient features of Chhattisgarh grid for the month of January to September 2018. The mean of absolute percentage error (APE) found to be $5.42 \%$. The minimum APE was $0.22 \%$ in the month of May and maximum APE was $12.35 \%$ in the month of June.
Table 1: Energy Requirement (Mus) and Peak Demand (MW) during year 2017 to year 2018 in Chhattisgarh state grid

\begin{tabular}{|c|c|c|c|c|c|c|}
\hline \multicolumn{4}{|c|}{$\begin{array}{c}\text { Unrestricted Energy } \\
\text { requirement }(\mathrm{Mu})\end{array}$} & \multicolumn{3}{|c|}{$\begin{array}{c}\text { Peak Demand Met } \\
(\mathrm{MW})\end{array}$} \\
\hline $\begin{array}{l}\text { Mon } \\
\text { th }\end{array}$ & $\begin{array}{l}\text { Yr. } \\
2014\end{array}$ & $\begin{array}{l}\text { Yr. } \\
2013\end{array}$ & $\begin{array}{l}\% \\
\text { Increa } \\
\text { se }\end{array}$ & $\begin{array}{l}\text { Yr } \\
2014\end{array}$ & $\begin{array}{l}\mathrm{Yr} \\
201 \\
3\end{array}$ & $\begin{array}{l}\% \\
\text { Increase } \\
\& \\
\text { APE }\end{array}$ \\
\hline $\begin{array}{l}\text { Janu } \\
\text { ary }\end{array}$ & $\begin{array}{l}1720 . \\
57\end{array}$ & $\begin{array}{l}1646 \\
.55\end{array}$ & $\begin{array}{l}4.50 \\
\%\end{array}$ & 3151 & $\begin{array}{l}296 \\
8\end{array}$ & $6.17 \%$ \\
\hline $\begin{array}{l}\text { Febr } \\
\text { uary }\end{array}$ & $\begin{array}{l}1578 . \\
79\end{array}$ & $\begin{array}{l}1536 \\
.34\end{array}$ & $\begin{array}{l}2.76 \\
\%\end{array}$ & 3210 & $\begin{array}{l}310 \\
5\end{array}$ & $3.38 \%$ \\
\hline $\begin{array}{l}\text { Marc } \\
\mathrm{h}\end{array}$ & $\begin{array}{l}1856 . \\
81\end{array}$ & $\begin{array}{l}1879 \\
.04\end{array}$ & $\begin{array}{l}- \\
1.18 \\
\%\end{array}$ & 3448 & $\begin{array}{l}323 \\
9\end{array}$ & $6.45 \%$ \\
\hline April & $\begin{array}{l}2001 . \\
17\end{array}$ & $\begin{array}{l}1834 \\
.44\end{array}$ & $\begin{array}{l}9.09 \\
\%\end{array}$ & 3487 & $\begin{array}{l}333 \\
1\end{array}$ & $4.67 \%$ \\
\hline May & $\begin{array}{l}1861 . \\
26\end{array}$ & $\begin{array}{l}1824 \\
.96\end{array}$ & $\begin{array}{l}1.99 \\
\%\end{array}$ & 3261 & $\begin{array}{l}325 \\
4\end{array}$ & $0.22 \%$ \\
\hline June & $\begin{array}{l}1682 . \\
73\end{array}$ & $\begin{array}{l}1450 \\
.49\end{array}$ & $\begin{array}{l}16.01 \\
\%\end{array}$ & 3138 & $\begin{array}{l}279 \\
3\end{array}$ & $12.35 \%$ \\
\hline July & $\begin{array}{l}1750 . \\
72\end{array}$ & $\begin{array}{l}1613 \\
.81\end{array}$ & $\begin{array}{l}8.48 \\
\%\end{array}$ & 3118 & $\begin{array}{l}305 \\
0\end{array}$ & $2.23 \%$ \\
\hline Aug & $\begin{array}{l}1815 . \\
14\end{array}$ & $\begin{array}{l}1525 \\
.88\end{array}$ & $\begin{array}{l}18.96 \\
\%\end{array}$ & 3354 & $\begin{array}{l}309 \\
1\end{array}$ & $8.51 \%$ \\
\hline Sept & $\begin{array}{l}1775 . \\
23\end{array}$ & $\begin{array}{l}1670 \\
.94\end{array}$ & $\begin{array}{l}6.24 \\
\%\end{array}$ & 3295 & $\begin{array}{l}314 \\
4\end{array}$ & $4.80 \%$ \\
\hline
\end{tabular}

The maximum demand of Chhattisgarh state met during April 2018 was 3487 MW on dated 21-04-2018 which is $4.68 \%$ more than April 2017 of $3331 \mathrm{MW}$. The maximum unrestricted demand during the month was 3628 MW on 04-04-2018 and minimum demand was 1902 MW on 14-04-2018. Similarly, the maximum demand of Chhattisgarh state met during May 2014 was 3261 MW on dated 12-05-2018 which is $0.22 \%$ more than May 2017 of 3254 MW. The maximum unrestricted demand during month was 3310MWon12-05-2018 and minimum demand met was $1776 \mathrm{MW}$ on 25 05-2018. The energy requirement for the MAY-14 was1861.26 MU which was $1.99 \%$ more than the requirement of $1824.96 \mathrm{MU}$ in MAY-17. Generation for about 10.35 $\mathrm{Mu} \& 1.797 \mathrm{Mu}$ was exercised during the 
month on state Generating units \& central power producers (CPP)/IPPs (Independent Power Producers) respectively totaling to12.147 Mu, as per the requirement of the system. Based upon the block wise frequency recorded in SCADA, grid Frequency remained in the IEGC (Indian electricity grid code) band of 49.9 to $50.05 \mathrm{~Hz}$ for $55.98 \%$ of time during the January to September 2018. Fig. 3.1 below shows the Chhattisgarh state power supply position. Chhattisgarh has met its maximum demand of $3459 \mathrm{MW}$ on dt.17.04.2017 and maximum energy consumption of 80.82 Mus achieved on 31st March, 2018. Fig 3.2 below shows the total peak demand and unrestricted demand met during year May 2107 to May 2018 [21].

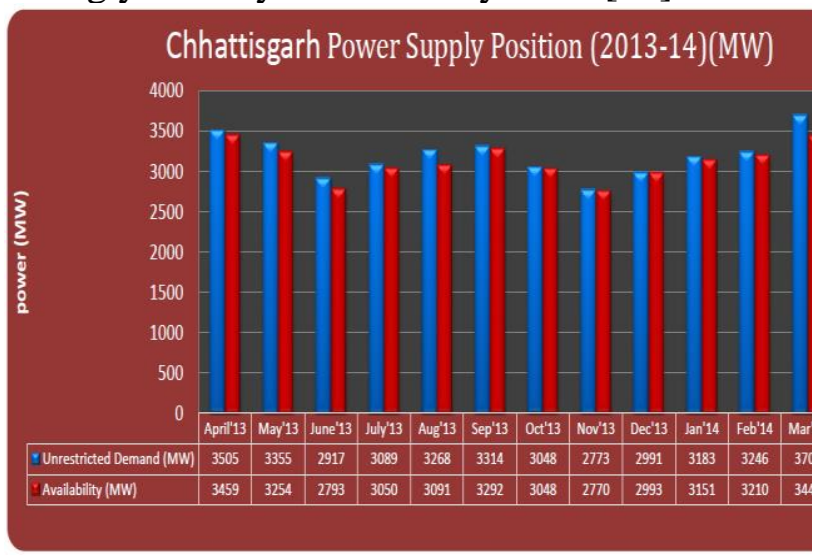

Fig. 3.1 Chhattisgarh state power supply position

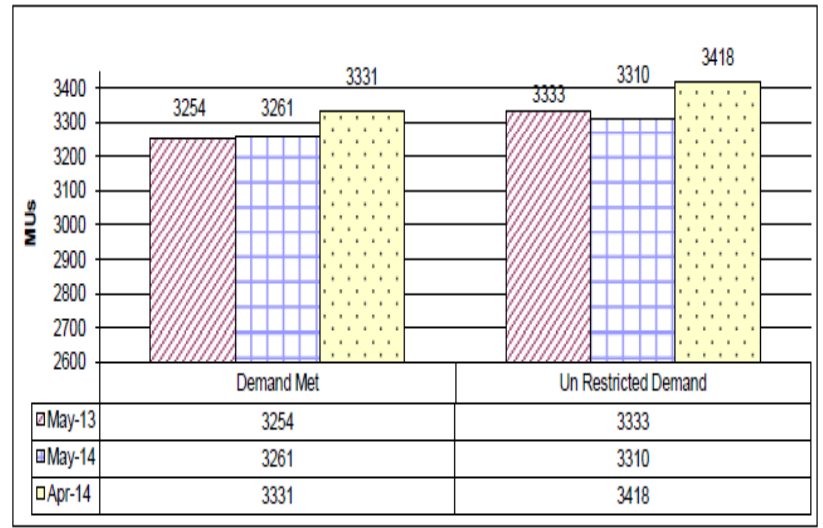

Fig. 3.2. Demand met in MW for year May 2018

Fig. 3.3 below shows the demand chart of year 2017-18 of western region which shows that power demand continuously increases while there is shortage of power.

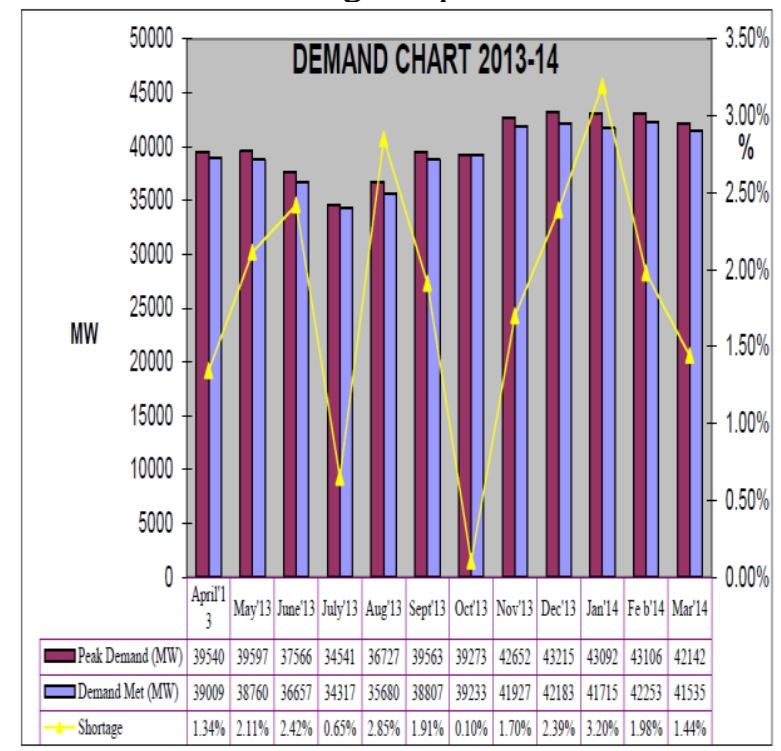

Fig 3.3 Demand chart for year 2017-18.

The Fig 3.4 below shows the annual load duration curve of western grid region of India from april 2017 to march 2018. The maximum demand met in the year 2017-18 was $42253 \mathrm{MW}$ on 11th Feb, 2018 at 11:00 hrs which is so far highest demand met in Western Region. Peak demand growth was $3.33 \%$ against last year whereas the unrestricted demand growth is $4.18 \%$. The minimum demand of $24713 \mathrm{MW}$ observed on 17th June 2017 at 05:00 Hrs. Compared to last year average shortage was reduced from $3.58 \%$ to $1.84 \%$ due to more capacity additions in 2017-18 as compared to 201617.

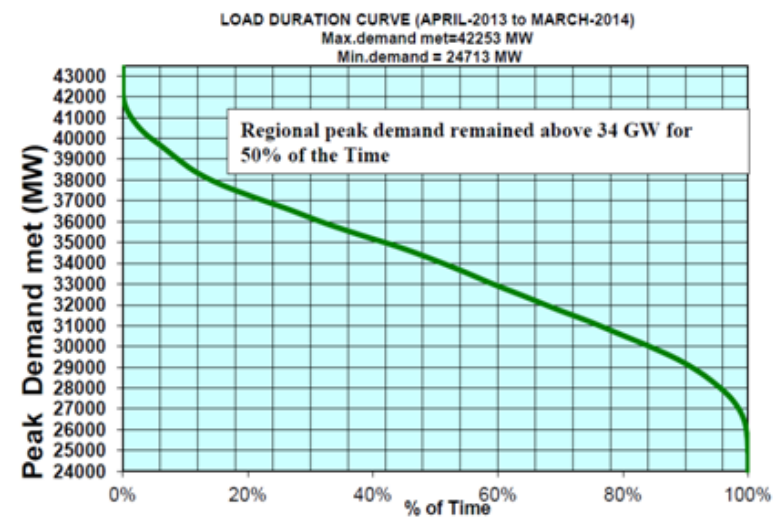

Fig.3.4 Load duration curve during year 2018 
To evaluate the ANN performance the percentage error is measured using, error $=$ (actual load - forecast load) / actual load. The multilayer feed forward network is used here which is three layer architecture with one input layer, one output layer and hidden layer. The optimum number of hidden layer found by trial and error such as geometric mean of input and output layer of neurons. Absolute error should be selected for better realization of the accuracy of forecasting results. For forecasting mean absolute percentage error (MAPE) is found to be best measure of performance evaluation. The MAPE value is the most common error indicator and generally accepted for comparing different forecast approaches. The input data is divided in three data sets, $70 \%$ for training, $15 \%$ for testing and $15 \%$ validation [12-21].

\section{Simulation Model and Results}

For developing the forecasting models we used the actual hourly and annually load data provided by Chhattisgarh state (India) load dispatch centre for the year 2017 through 2018. Inputs to the ANN are past loads of year 2017 and the outputs of the ANN are the load forecast for present month given. The simulation result for performance of network shown in fig.4.0 is carried out for peak demand of power data from January to September2017-18.

Regression $\mathrm{R}$ values measure the correlation between outputs and targets. $\mathrm{R}$ value of 1 means a close relationship, 0 a random relationship. Output tracks the target very well for training, testing and validation and $\mathrm{R}$ value is over 0.78 for total response. The network response is satisfactory.

The training state of neural network shown in fig.4.1 and regression plot of network training for actual load data and forecast load data shown in fig. 4.2 below

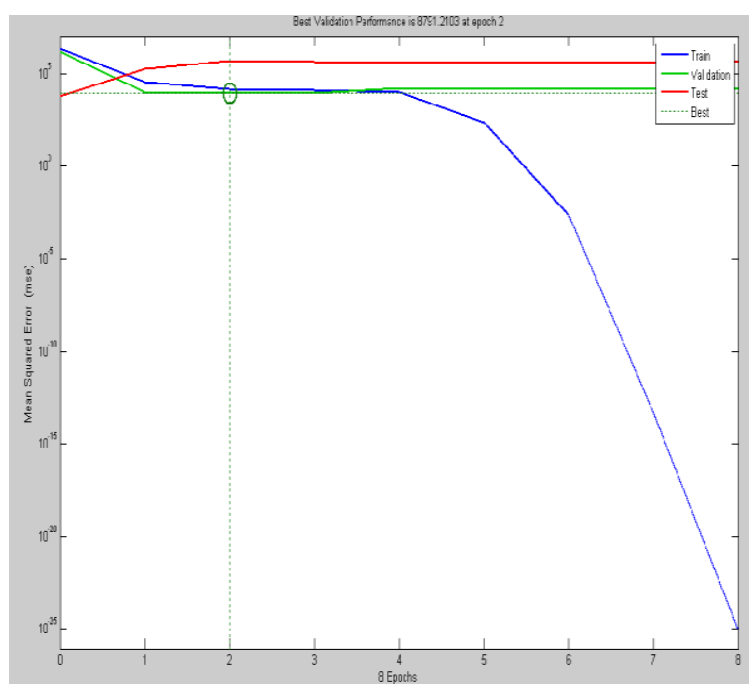

Fig.4.0 Performance of the network1 for peak demand power data from Jan.- Sept. 2017-18.

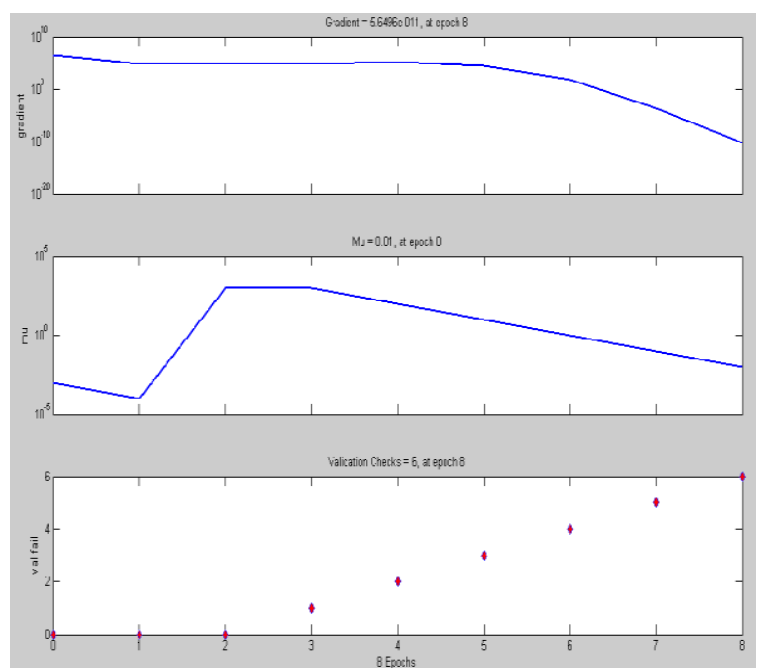

Fig.4.1 Training state of neural network
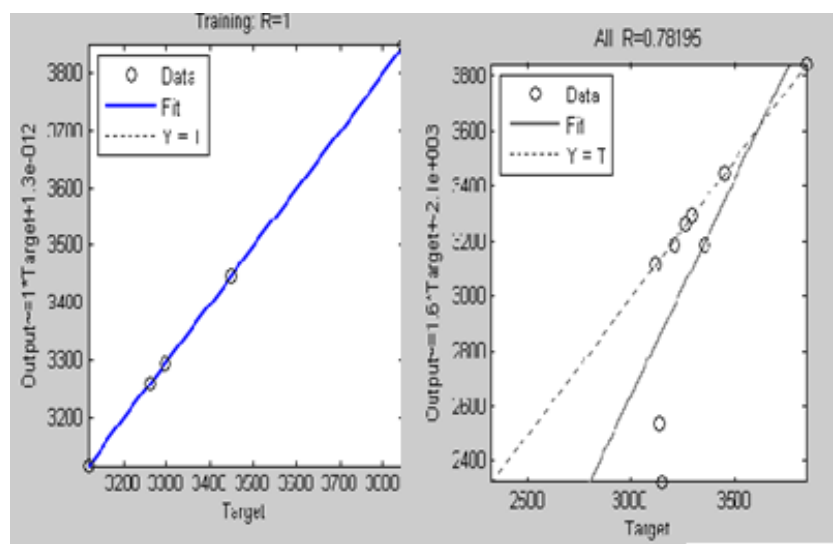

Fig.4.2 Regression plot of actual load and forecast load data. 
Table 2: Feed forward neural network (FNN) evaluation for Regression

\begin{tabular}{|l|l|l|}
\hline $\mathbf{R}$ & MSE & MAPE \% \\
\hline 0.7896 & 3150 & 3.962 \\
\hline
\end{tabular}

Table II presents the mean square error is 3150 and mean absolute percentage error (MAPE) is $3.962 \%$. The minimum absolute percentage error (APE) is found $0.1908 \%$ and maximum APE found as $11.33 \%$.

The neural network implementation is achieved with initialization of neural networks, training of neural networks and simulating (testing) of the trained network. For simulation the feed forward back propagation algorithm is used. The training function is trainlm, adaptive learning function is learngdm, performance function is MSE, number of layers 2, number of neurons used in training is 10 and the transfer function is tansig. The neural network1training gives best validation performance is 8791.2103 at epoch 2 shown in fig 4.0.

\section{Conclusion}

Artificial neural networks have been effective for learning functional mappings between input and output target variables. This is done by adjusting weights of a set of interconnected neurons by learning rules. The backpropagation technique used here for training. Its forecasting reliabilities evaluated by computing the minimum APE which was obtained to be $0.1908 \%$ and MAPE $3.962 \%$ which represents a high degree of accuracy. In this paper load flow data for short term load forecasting has collected for future prediction and it can be observed that ANN base forecasted electrical load profiles seem to be closer to the actual load profiles than classical methods. Electrical load forecasting has provided several advantages for saving and efficiently helpful to transmit the electric power. It will be concluded that electric load forecasting is an essential elements of power systems operation and planning for future demand, planning for transmission and distribution systems as well as new generation power plants.

The performance of the developed method for short term load forecast is tested using power load data which is collected from Chhattisgarh load dispatch centre Raipur of western region (India) and the results obtained by neural network method are compared by linear regression method for short term load forecasting. The results show that network has a good performance and reasonable prediction and finally this neural network could be an important tool for short term load forecasting. The precise prediction can help electricity market to make better decision to increase their benefits.

\section{Conflict of interest}

The author declares no conflict of interest.

\section{References}

[1] Quan, H. Srinivasan D. ; Khosravi A." Short-Term Load and Wind Power Forecasting Using Neural Network-Based Prediction Intervals" Volume:25 Issue:2, Page(s):303 - 315, ISSN :2162-237X, Feb. 2014.

[2] Chaouch, M, "Clustering-Based Improvement of Nonparametric Functional Time Series Forecasting: Application to Intra-Day Household-Level Load Curves" Smart Grid, IEEE Transactions, Volume:5 Issue:1, Page(s): 411 - 419, ISSN : 19493053, Jan. 2014.

[3] Licciardi G. A. St. Martind 'Hères Dambreville, R. Chanussot, J. Dubost, S., 2015. Spatiotemporal Pattern Recognition and Nonlinear PCA for Global Horizontal Irradiance Forecasting" Geoscience and Remote Sensing Letters ,IEEE 12(2)284 288. 
[4] Galvan E.; Gutierrez Alcaraz, G. ; Gonzalez Cabrera, N., 2015 "Two-phase Short-term Scheduling Approach with Intermittent Renewable Energy Resources and Demand Response" Revista IEEE AmericaLatina, 13(1),181 - 187, ISSN :15480992.

[5] Quilumba, F. L. Wei-Jen Lee Wang, D.Y., 2014 "Using Smart Meter Data to Improve the Accuracy of Intraday Load Forecasting Considering Customer Behavior Similarities" Smart Grid, IEEE Transactions on 6(2), 911 - 918, ISSN: 1949-3053.

[6] Black, J. D. Henson, W.L.W. 2014 Hierarchical Load Hindcasting Using Reanalysis Weather" Smart Grid, IEEE Transactions on 5(1),:447 - 455, ISSN :1949-3053.

[7] Gu C. Dazhi Y. Jirutitijaroen, P. ; Walsh, W.M. 2014. Spatial Load Forecasting With Communication Failure Using Time-Forward Kriging" Power Systems, IEEE Transactions 29(6,) $2875-2882$.

[8] Lee, K.Y. Park, J. H. 1992. "Short term Load forecasting using an ANN" IEEE Transaction on power system 7(1), 124-132, ISSN 0885-8950.

[9] Chaturvedi, D. K. Mohan,M. Singh, R. K. and Kalra, P. K. 2004. "Improved generalized neuron model for short term load forecasting," International Journal on Soft Computing-A FFMA, Springer, 8(1)10-18.

[10] Natessan, R., Radman G. 2004. Effects of STATCOM, SSSC and UPFC on voltage stability", IEEE Transaction on Power Systems, 4,546-550.

[11] Dipen A. Mistry, Bhupelly Dheeraj, Ravit Gautam, Manmohan Singh Meena, Suresh Mikkili, "Power Quality Improvement Using PI and Fuzzy Logic Controllers Based
Shunt Active Filter " WASET, International Journal of Electrical, Robotics, Electronics and Communications Engineering Vol:8,pp410, 2014.

[12] Jain, A., Choi, J., \& Min, J. (2002, October). Power system network observability determination using feedforward neural networks. In Proceedings. International Conference on Power System Technology (Vol. 4, pp. 20862090). IEEE.

[13] Islam, B. U. (2011). Comparison of conventional and modern load forecasting techniques based on artificial intelligence and expert systems. International Journal of Computer Science Issues (IJCSI), 8(5), 504513.

[14] Dopazo, J. F., Dwarakanath, M. H., Li, J. J., \& Sasson, A. M. (1977). An external system equivalent model using real-time measurements for system security evaluation. IEEE Transactions on Power Apparatus and Systems, 96(2), 431-446.

[15] Dillon, T. S. (1993). "Artificial neural network applications to power systems and their relationship to symbolic methods", International Journal of Electric Power and energy system, Vol. 2, 1533-1536.

[16] Chaturvedi, D. K., Satsangi, P. S., \& Kalra, P. K. (2001). Fuzzified neural network approach for load forecasting. Engineering Intelligent Systems, 9(1), 3-9.

[17] El Desouky, A. A., \& El Kateb, M. M. (2000). Hybrid adaptive techniques for electric-load forecast using ANN and ARIMA. IEE Proceedings-Generation, Transmission and Distribution, 147(4), 213217.

[18] Manchanda, P., Kumar, J., \& Siddiqi, A. H. (2007). Mathematical methods for 
modelling price fluctuations of financial times series. Journal of the Franklin Institute, 344(5), 613-636.

[19] Kumar, P. and Mahajan, A. 2009. Soft Computing Technics for the control of an Active Power Filter, IEEE Transaction on Power Delivery, 24 (1-5).

[20] Mishra, D. K. Dwivedi AK D. 2012. Efficient journal of latest algorithm for load forecasting in electrical power system" International journal of latest research in science \& technology, 3, 6-11, ISSN 22785299.

[21] Hingorani, N.G. and Gyugyi, Understandind L. FACTS, concepts and technology of flexible AC Transmission, IEEE Press 2000, New York.

[22] http://www.wrldc.com/onlinestate.aspx, www.csptcl.com.

[23] Ghritlahre, H.K. and Prasad, R.K. 2018. Application of ANN technique to predict the performance of solar collector systems - a review. Renewable and Sustainable Energy Reviews, 84, 75-88.

[24] Ghritlahre, H.K., Prasad, R.K. 2018. Investigation of thermal performance of unidirectional flow porous bed solar air heater using MLP, GRNN, and RBF models of ANN technique. Thermal Science and Engineering Progress, 6, 226-235.

[25] Ghritlahre, H.K., Chandrakar, P., Ahmad, A. 2019. A comprehensive review on performance prediction of solar air heaters using artificial neural network. Annals of Data Science, 1-45.

https://doi.org/10.1007/s40745-019-00236-1

[26] Ghritlahre, H.K. 2019. Performance prediction of porous bed solar air heater using MLP and GRNN model-A comparative study. CSVTU Research Journal on Engineering and Technology ,8 (1), 70-81. [27] Ahmad, A., Ghritlahre, H. K., and Chandrakar, P. (2020). Implementation of ANN technique for performance prediction of solar thermal systems: A Comprehensive Review. Trends in Renewable Energy, 6, 1236. DOI: 10.17737/tre.2020.6.1.00110 